\title{
Assessment Of Student Performance And Attitudes For Courses Taught Online Versus Onsite
}

Michael C. Campbell, (email: mcampbell@msubillings.edu), Montana State University Joe Floyd (email: jfloyd@msu-b.edu), Montana State University

Joanne B. Sheridan (email: jsheridan@msubillings.edu), Montana State University

\begin{abstract}
This paper assesses the differences in performance and attitudes of students taught online versus onsite. Students completed a course evaluation designed to determine student satisfaction in specific areas. Student performance was measured by means of a comprehensive exam that tested all material covered in the course. Results support the contention that students in online courses learn as much or more than students in traditional onsite courses and are as satisfied with the course and the instruction as their onsite counterparts.
\end{abstract}

\section{Introduction}

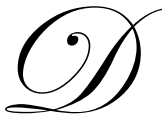

istance education is not a new phenomenon, and has been practiced in one form or another since the early 1900s (Moore and Kearsley, 1996). The interest in and development of distance learning is predicted to continue to grow in the $21^{\text {st }}$ century as various social and economic trends drive its development. Department of Education statistics suggest that college enrollments will hit approximately 20 million by 2010 due to the predicted growth of high school graduating classes (more than 20 percent between 19962005), the greater proportion of high school graduates that are enrolling in college (67 percent) and the increase in nontraditional college students, a phenomenon fueled by changes in employment and wage structures of the American economy. State governments have begun investing in distance learning programs instead of enlarging traditional campuses because of budgetary constraints and the need to provide service to large, sparsely populated geographic areas. Cultural and lifestyle changes are also playing an increasing role in the development of distance learning as flexibility and convenience replace the students' needs for connectivity (AAUP, 1997).

While there is a long and well-established history of studying the efficacy of teaching and learning at a distance, the research outcomes are varied. By 1977, however, there was agreement among researchers that whether a student learns more from one medium than from another is at least as likely to depend on how the medium is used as on what medium is used (Schramm). Several studies that compare cognitive factors such as, academic performance, achievement, examination results and grades in distance learning in general found no differences in cognitive factors. (Nunley, 1965; Kuramato, 1984; Weingand, 1984; McCleary and Egan, 1989; Pirrong and Lathen, 1990; Souder, 1993; Naber; LeBlanc 1994; Spooner, et. al. 1999; and Carswell, et. al. 2000).

Research on other factors such as student satisfaction with the course has yielded more mixed results. Davis (1984), Ritchie and Newby (1989), and Pirrong and Lathen (1990) found that distance-learning students were less satisfied with their distance learning classes than students in traditional classrooms. On the other hand, Jones (1992), Stahmer, et.al. (1992), Goodwin, et.al. (1993), and Naber and LeBlanc (1994) found students'

Readers with comments or questions are encouraged to contact the authors via email.

attitudes favorable to distance learning. The findings of some studies such as Kuramato (1984) were mixed and inconclusive. Other research indicated that faculty and students showed more favorable attitudes towards teaching and learning through distance learning once they had experience in teaching a course or taking a course in a distance learning format (Carswell, et.al, 2000; and Sonner, 1999). 
The online distance-learning program at the authors' university began in 1998 with five courses and 16 students, and has grown to over 100 courses and 1850 students. In spring 2001, three online degree programs, at least one course in every category of the general education core and most business common body of knowledge (CBK) courses were offered online.

In an effort to insure that student learning and student satisfaction in the online courses were commensurate with traditional onsite instruction, or at least at an acceptable level, the accounting faculty developed an assessment program to study the performance and attitudes of online students compared to traditional onsite students.

Principles of Accounting I was the initial accounting course that was developed and offered online in fall 2000 using the eCollege Internet distance-learning platform. This platform allows standard Internet distance learning features such as chats, threaded discussions, online quizzes and exams and access to text, PowerPoint presentations, homework solutions, and other resource material. This paper assesses the differences in student performance and attitudes between the online course offered via the Internet versus a traditional onsite course.

Six course sections were involved. Five sections were taught onsite by two different instructors. One section, taught by a different instructor, was taught in an online format. All instructors were experienced in teaching the Principles of Accounting I course. Due to dissatisfaction with the previously used text, a new text was selected and used for the first time during this fall term. The text, Financial Accounting, seventh edition by Needles and Powers was a new edition in fall 2000, which did cause some difficulty, as some materials were not available as soon as expected.

To achieve some consistency the instructors adopted a common syllabus, covered the same chapters and gave the same homework assignments. However, homework collection and credit policies varied. Each instructor prepared his or her own exams, except for the comprehensive portion of the final exam. Chapter quizzes were given as teaching aids and to allow students to assess their progress, but were not considered in determining grades.

Onsite instruction included traditional lecture/discussion as well as in-class group activities and homework review. Online instructional material was available from the publisher. It included a comprehensive summary for each learning objective in each chapter and a PowerPoint slide presentation, which covered the same material but in a different way. Use of these materials by online students was optional. No data was collected on the amount of time students spent on these materials.

Online instruction also included seven one-hour full-class "chats" during which the students and the instructor were all online in a chat group and could communicate by typing comments that everyone could see. During chats, students were encouraged to ask questions, which they often did, and the instructor also posed questions for discussion. About half the class usually participated in the chats. Students who did not join the chats supposedly had unavoidable conflicts. Attempts to create small chat groups of 4 to 5 students were not successful, although a few students did develop informal relationships and emailed each other to discuss problems. Threaded discussions were not used. Students also were encouraged to email the instructor or to call by telephone, or arrange a time for the instructor to call them. Email questions from students averaged about 10 per week. The telephone option was used only a few times.

Table 1.

Demographic information for students who completed the Course and Instructor Evaluation is presented in

Table 1

Students Who Completed the Course and Instructor Evaluation

\begin{tabular}{|c|c|c|c|c|c|c|c|c|}
\hline \multirow[b]{2}{*}{ Section } & \multicolumn{3}{|c|}{ By Gender } & \multicolumn{5}{|c|}{ By Class Level } \\
\hline & Male & Female & Total & $\mathrm{Fr}$ & Soph & $\mathrm{Jr}$ & $\mathrm{Sr}$ & Other \\
\hline
\end{tabular}




\begin{tabular}{|c|c|c|c|c|c|c|c|c|}
\hline 1 & 10 & 14 & 24 & 7 & 10 & 6 & 1 & 0 \\
\hline 2 & 9 & 15 & 24 & 14 & 5 & 2 & 0 & 3 \\
\hline 3 & 5 & 7 & 12 & 1 & 8 & 1 & 0 & 2 \\
\hline 4 & 7 & 7 & 14 & 3 & 4 & 2 & 2 & 3 \\
\hline 5 & 7 & 6 & 13 & 3 & 4 & 6 & 0 & 0 \\
\hline Total Onsite & 38 & 49 & 87 & 28 & 31 & 17 & 3 & 8 \\
\hline $6^{*}$ & 3 & 11 & 14 & 6 & 2 & 4 & 0 & 2 \\
\hline Total & 41 & 60 & 101 & 34 & 33 & 21 & 3 & 10 \\
\hline
\end{tabular}

The overall ratio of males to females is representative of the population at the University. The difference in male-female ratios in online vs. onsite courses was not significant at the .05 level. The class levels of the students are typical for Principles of Accounting I courses, and once again the difference for online and onsite was not significant at the .05 level. The indicated class sizes are small, because all students did not complete the evaluation and because, traditionally, about $30 \%$ of students who start the Principles of Accounting I course, drop out before the final exam.

The number of students who took the final exam was 134: 120 onsite, and 14 online. Thus, 33 students who took the final exam did not complete the Course and Instructor Evaluation.

\section{Assessment}

Two instruments were used in this study: one to assess student attitudes and one to assess student performance. Student attitudes will be discussed first.

Since the online program at our University has its own student attitude assessment form, this form was used without modification to assess student attitudes in the online course. The assessment was done in the normal way via the Internet by the online administrative staff. However, because some questions pertain only to online issues, these questions were deleted in developing the instrument for onsite use. Since the objective was to make comparisons between the two types of instruction, results of the online-specific questions were ignored for this study, and only the responses to questions used in both online and onsite classes are included in this assessment. Table 2 is shown below in landscape format and contains an analysis of student responses to the Course and Instructor Evaluation. The response scales differed by question. A legend explaining the responses is provided at the bottom of Table 2. Generally the first response (e.g., Very Good) indicates greater satisfaction. The numerical scale goes from 1 to 5 , with 1 generally indicating greatest satisfaction and 5 indicating greatest dissatisfaction.

Only the response to question number 3 had a significant difference at the .05 level. Students in the online course felt the instructor was more available/approachable for dealing with course questions, problems and issues. Question 18 had a response difference that was significant at the .06 level. Students in the onsite course felt they had better interaction with their fellow students. None of the response differences on the remaining 17 questions were significant even at the .10 level. On these questions online students were more satisfied in 10 areas, while onsite students were more satisfied in 7 areas. Overall, students seem to have been neither more nor less satisfied with online instruction versus onsite instruction.

Table 2

Analysis of Responses to Student Course and Instructor Evaluation

\section{Response Means}

\begin{tabular}{|c|c|c|c|c|c|}
\hline Q\# & Onsite & Online & Sig. & $\underline{\text { Scale }}$ & Question \\
\hline 3 & 2.42 & 1.79 & 0.016 & VG & $\begin{array}{l}\text { Instructor was available/approachable for dealing with questions, problems, } \\
\text { etc. }\end{array}$ \\
\hline 4 & 1.81 & 1.64 & 0.523 & VG-VP & Knowledgeable/competent for instruction in the course area \\
\hline
\end{tabular}




\begin{tabular}{|c|c|c|c|c|c|}
\hline 5 & 2.73 & 2.29 & 0.213 & VG-VP & Caring/concerned about my progress/performance in the course \\
\hline 6 & 2.08 & 1.93 & 0.588 & VG-VP & Enthusiastic/genuinely interested in teaching the course \\
\hline r & 2.74 & 2.79 & 0.871 & OB-FBA & Compared with all other college instructors I have had, this instructor was \\
\hline 8 & 1.87 & 2.15 & 0.201 & SA-SD & The course goals were clearly identified/explained \\
\hline 9 & 1.93 & 2.54 & 0.134 & SA-SD & The course appears to have been carefully planned/facilitated \\
\hline 10 & 2.43 & 2.77 & 0.342 & SA-SD & The course lessons/materials were clear and easy to follow \\
\hline 11 & 2.58 & 2.38 & 0.608 & SA-SD & $\begin{array}{l}\text { The course was facilitated in a way that made me feel free to ask questions, } \\
\text { express my ideas, disagree }\end{array}$ \\
\hline 12 & 1.89 & 1.85 & 0.892 & SA-SD & The course material was challenging/ demanding/intellectually stimulating \\
\hline 13 & 1.74 & 2.08 & 0.150 & SA-SD & The course assignments were useful in learning the material \\
\hline 14 & 2.33 & 2.08 & 0.476 & SA-SD & The course schedule was demanding but adequately flexible \\
\hline 15 & 2.26 & 2.46 & 0.348 & FTF-FTS & The pace of this course was \\
\hline 16 & 2.51 & 2.31 & 0.315 & TH-TL & The "work load" level of class assignments/projects was \\
\hline 17 & 2.28 & 2.46 & 0.621 & SA-SD & $\begin{array}{l}\text { The course assignments were fair and appropriate methods for evaluating my } \\
\text { performance in the class }\end{array}$ \\
\hline 18 & 2.20 & 3.00 & 0.056 & VG-VP & The interaction that I had with other students in this course was \\
\hline 19 & 2.69 & 2.38 & 0.360 & VG-VP & The interaction that I had with the course instructor was \\
\hline 20 & 2.75 & 2.54 & 0.578 & VG-VP & The amount/quality of feedback I received from the course instructor was \\
\hline 21 & 2.11 & 2.08 & 0.918 & VG-VP & $\begin{array}{l}\text { Rate the course materials/resources (text, readings, web site, etc.) in terms of } \\
\text { their overall quality for enhancing your learning experience }\end{array}$ \\
\hline
\end{tabular}



The second purpose of the study was to assess student performance, that is, the degree to which students learned the course material. A comprehensive final exam was developed for this purpose. It consisted of $40 \mathrm{mul}$ tiple choice questions from the authors' test bank. Questions were chosen for each of the 12 chapters covered in the course and were selected to address the main points of each chapter. Although some questions were computational, there were fewer computational and more conceptual questions than would be typical on a mid-course exam covering only 3 or 4 chapters. All three instructors reviewed the proposed exam, and changes were made based on suggestions from each instructor. The results on the comprehensive final exam are presented in Table 3.

Table 3

Analysis of Scores on Comprehensive Final

Part I

Comparison of Average Number of Correct Responses Out of 40 Questions

(Difference is Significant at the .000 Level)

\begin{tabular}{|c|c|c|c|}
\hline & \multicolumn{3}{|c|}{ Average Number of Cor- } \\
\hline & $\underline{\text { No. of Students }}$ & rect Responses & $\%$ Correct \\
\hline Onsite & 120 & 24.4 & 64.0 \\
\hline Online & 14 & 31.3 & 78.3 \\
\hline Total & 134 & & \\
\hline
\end{tabular}

Part II

Questions with a Difference in Average Number of Correct Responses of $20 \%$ points or More for Onsite vs. Online Students 
$\%$ Correct

\begin{tabular}{|c|c|c|c|c|c|}
\hline$\underline{\mathrm{Ch} \#}$ & $\mathrm{Q} \#$ & Onsite & Online & $\underline{\text { Significance Level }}$ & Topic Area of Question \\
\hline 1 & 3 & 66 & 86 & 0.23 & $\begin{array}{l}\text { Main purpose of financial state- } \\
\text { ments }\end{array}$ \\
\hline 2 & 5 & 55 & 79 & 0.16 & Impact on retained earnings \\
\hline 4 & 11 & 65 & 93 & 0.07 & Accounting cycle \\
\hline $5 *$ & 13 & 47 & 100 & 0.0005 & Objectives of financial reporting \\
\hline 5 & 14 & 57 & 93 & 0.02 & $\begin{array}{l}\text { Characteristics of accounting in- } \\
\text { formation }\end{array}$ \\
\hline 5 & 16 & 53 & 86 & 0.04 & Calculate working capital \\
\hline 6 & 17 & 70 & 100 & 0.04 & Definition of gross margin \\
\hline 6 & 20 & 15 & 36 & 0.12 & Definition of internal control \\
\hline 7 & 22 & 38 & 93 & 0.0002 & Valuation of trading securities \\
\hline 7 & 23 & 55 & 79 & 0.16 & $\begin{array}{l}\text { Reason for allowance for uncol- } \\
\text { lectible accounts } \\
\text { Calculate ending inventory: peri- }\end{array}$ \\
\hline 8 & 26 & 56 & 79 & 0.17 & odic, average cost \\
\hline 9 & 28 & 78 & 100 & 0.10 & $\begin{array}{l}\text { When to recognize a liability } \\
\text { Matching principle and warranty }\end{array}$ \\
\hline 9 & 31 & 46 & 100 & 0.0004 & expense \\
\hline 10 & 33 & 69 & 93 & 0.12 & $\begin{array}{l}\text { Items to include in the cost of a } \\
\text { machine }\end{array}$ \\
\hline 11 & 35 & 44 & 79 & $\mathbf{0 . 0 3}$ & $\begin{array}{l}\text { Advantages of issuing long-term } \\
\text { debt }\end{array}$ \\
\hline 12 & 40 & 48 & 79 & 0.06 & Net effects of a cash dividend \\
\hline
\end{tabular}

* Chapter 5 is Financial Reporting and Analysis. It includes objectives, characteristics and conventions related to financial statements, classified balance sheet and income statement, and analysis of financial statements.

Table 3 compares the test results in two ways. Part I is a comparison of the average number of correct responses on the 40-question exam and the average score in percent. Onsite students answered an average of 24.4 questions correctly (64.0\%), while online students answered an average of 31.3 questions correctly (78.3\%). This difference is significant at the .000 level and is the most statistically significant finding in this study. Reasons for this difference could include differences in student motivation and ability. Online students may have spent more time studying the material and may have completed a greater portion of the homework. Perhaps the online materials and activities have greater educational value than the traditional materials and classroom activities used in the onsite classes. These possibilities are not addressed in this study. The reasons for the better performance of the online students are unknown.

Part II of Table 3 presents individual questions from the exam on which there was a difference in average number of correct responses of 20 percentage points or more for onsite versus online students. Differences that are significant at the .05 level are shown in bold in the Significance Level column in the table. The online students performed better than the onsite students on all of the questions included in the table. For questions not included in the table, online students performed better on most, but not all, of the questions. A review of the questions showing significant differences did not yield any consistency in type of question or topic area, except for questions relating to financial reporting and analysis (Chapter 5), on which online students were clearly superior. The reason for this is not known.

\section{Conclusions}

In this study students appear equally satisfied with online and onsite courses. However, online students performed significantly better on a comprehensive multiple-choice exam, and thus, presumably learned more of the subject matter than their onsite counterparts. This result was not expected. It may be explained by differences in the two student groups that were not addressed by the study. Individual motivation and ability of the students probably 
account for at least some of the difference. Variables such as age, major and grade point average could be collected in future studies to try to address possible differences in motivation and ability.

\section{Recommendations for revisions to current project}

1. Continue the project through spring 2002. Collect and analyze data on age, major, and grade point averages for all students.

2. Include an analysis of student comments on the evaluation form.

3. Collect data on retention rates of students in the online and onsite courses.

4. Consider alternative methods of measuring student performance in addition to the comprehensive multiplechoice exam.

5. Attempt to enhance consistency between the online and onsite courses by adopting policies on homework collection and credit for assignments and quizzes.

\section{Recommendations for future research}

1. Compare the performance and attitudes of online and onsite students in other business courses.

2. Assess the performance in subsequent courses of students who have taken core courses online versus onsite.

3. Identify the characteristics of students and teachers that affect the likelihood of success in online courses.

\section{References}

1. American Association of University Professors (AAUP) (1997). Committee R on Government Relations. Report on distance learning.

2. Carswell, L., Thomas, P., Petre, M., Price, B., and Richards, M. (2000) Distance education via the Internet: the student experience. British Journal of Education Technology, 29-46.

3. Davis, D. J. (1984). Evaluation and comparison of teleconference training with face-to-face training and the effects on attitude and learning. Dissertation Abstracts International, 46, (No. AAC850579).

4. Goodwin, B. N. , Miklich, B. A., and Overall, J. U. (1993). Perceptions and attitudes of faculty and students in two distance learning modes of delivery: online computer and telecourse. (ERIC Document Reproduction Services No. ED371 708).

5. Jones, T. (1992). Students' evaluation questionnaire for the fall semester of 1991. A summary and report. (ERIC Document Reproduction Services No. ED 345 716).

6. Kuramato, A. (1984). Teleconferencing for nurses: evaluating its effectiveness. In L. Parker and C. Olgren (Eds.), Teleconferencing and electronic communications III. Madison: University of WisconsinExtension, Center for Interactive Programs.

7. McCleary, I. D., and Egan, M. W. (1989). Program design and evaluation: two-way interactive television. The American Journal of Distance Education, 3(1), 50-60.

8. Moore, M. G. and Kearsley, G. (1996). Distance Education: A Systems View. Belmont, CA: Wadsworth.

9. Naber, D., and LeBlanc, G. (1994). Providing a human biology laboratory for distant learners. The American Journal of Distance Education, 8(2), 58-70.

10. Nunley, B. G. (1965). A study of effectiveness of telelecture in the retraining of elementary teachers in mathematics. Doctoral dissertation. University of Texas.

11. Pirrong, G., and Lathen, W. (1990, May). The use of interactive television in business education. Educational Technology, 49-54.

12. Ritchie, H., and Newby, T. J. (1989). Classroom lecture/discussion vs. live televised instruction. A comparison of effects on student performance, attitude, and interaction. The American Journal of Distance Education 3 (3). 36-45.

13. Schramm, Wilbur. (1977). Big Media, Little Media. Beverly Hills: Sage.

14. Sonner, B. S. (1999). Success in the capstone business course-assessing the effectiveness of distance learning. Journal of Education for Business. 74(4) 243-47.

15. Souder, W. E. (1993). The effectiveness of traditional vs. satellite delivery in three management of tech- 
nology master's degree programs. The American Journal of Distance Education, 7(1), 37-53.

16. Spooner, F., Jordan, L., Algozzine, B., and Spooner, M. (1999, January/February). Student ratings of instruction in distance learning and on-campus classes. Journal of Educational Research, 92(3), 132-40.

17. Stahmer, G., Samaldino, S., Hardman, R., and Muffaletto, R. (1992 February). A survey of students currently enrolled in interactive instructional television courses in community colleges in Iowa. Paper presented at the annual meeting of the Association for Educational Communications and Technology, Washington, DC.

18. Weingand, D. E. (1984). Telecommunications and the traditional classroom: A study of the delivery of education. In L. Parker and C. Olgren (Eds.), Teleconferencing and electronic communications III. Madison: University of Wisconsin-Extension, Center for Interactive Programs.

Notes 